\section{Considerações sobre a formação do professor de inglês em um mundo globalizado*}

Considerations on English teacher training in a globalized
Bárbara Cristina GALLARDO (Unemat) barbarag@unemat.br

Wélica Cristina Duarte de OLIVEIRA (Unemat/ SEDUC-MT) welicacd@gmail.com

Recebido em: 30 de maio de 2018. Aceito em: 13 de out. de 2018.

*Este trabalho foi realizado com o apoio do CNPq, processo 42698[429411/2016-2].
GALLARDO, Bárbara Cristina;

OLIVEIRA, Wélica Cristina Duarte de. Considerações sobre a formação do professor de inglês em um mundo globalizado. Entrepalavras, Fortaleza, v. 8, n. 3 , p. $300-319$, out-dez/2018.

Resumo: Considerando as constantes mudanças nas formas de aprender e ensinar, argumentamos que as disciplinas de Prática de Ensino e Estágio dos Cursos de Letras (português/inglês) devem estar atentas às novas demandas das salas de aula/sujeitos. Dessa forma, a promoção do diálogo entre teoria e práticas contemporâneas que desafiam os métodos tradicionais de ensino se faz necessário. Neste artigo, apontamos, a partir de nossa experiência como formadoras de professores de línguas, a distância entre a concepção interacional da língua e a prática de ensino. Tal prática é ainda apresentada e internalizada como mero instrumento, por professores em formação. Constatamos, durante o acompanhamento desses professores, a necessidade do desenvolvimento das competências linguística e pedagógica ao longo de sua formação. Baseando-nos nos pressupostos da linguística aplicada (LEFFA, 2016; PAIVA, 2011), apresentamos a primeira versão de dois planos de aula, a fim de apontar: i) presença/ausência dessas duas competências e ii) a(s) concepção(ões) de língua privilegiadas. Os resultados sugerem que o ensino restrito da 'forma' da língua ainda é uma tendência que pode, entre algumas razões, estar ligada à falta da competência linguística; que o domínio das duas competências amplia o escopo de ensino/ 
aprendizagem para além da sala de aula de línguas. Em um mundo conectado, as práticas digitais aliadas às competências propostas neste artigo podem fortalecer os cursos de licenciatura em línguas e, consequentemente, tornar a disciplina de língua inglesa protagonista na escola. Alguns autores que embasam este estudo são Gimenez (2013), Miccoli (2013), Monte Mor (2015), Moita Lopes (2013) e Pennycook (2017).

Palavras-chave: Estágio supervisionado. Formação de professor de inglês. Prática de ensino de língua inglesa.

Abstract: Considering the constant changes in ways of learning and teaching, we argue that the Arts and Literature undergraduate program's subjects of Teaching Practice and Supervised Internship should be attentive to the new demands of classrooms / subjects. Thus, the promotion of the dialogue between theory and contemporary practices that challenge traditional methods of teaching foreign languages is necessary. In this article, we point out, from our experience as teacher trainers, the distance between the interactive conception of language and the practice of language teaching. Such practice is still presented and internalized as a mere instrument by teachers in training. We verified the need to develop linguistic and pedagogical skills throughout teacher training. Based on the assumptions of applied linguistics (LEFFA, 2016; PAIVA, 2011), we present the first version of two lesson plans, in order to point out: i) presence / absence of these two competences ii) the conception(s) of language which is privileged in these plans. The results suggest that the restricted teaching of the 'form' of the language is still a trend that may, among other reasons, be linked to the lack of linguistic competence; the mastery of these two competences expands the scope of teaching/learning beyond the language classroom. In a connected world, the digital practices allied to the competences proposed in this article can strengthen undergraduate courses and, consequently, make the English discipline protagonist in school. Among the authors that base this study are Gimenez (2013), Miccoli (2013), Monte Mor (2015), Moita Lopes (2013) and Pennycook (2017).

Keywords: Teaching internship. Teacher training. English language teaching practice.

\section{Introdução}

Lecionar em uma sala de aula de ensino fundamental e médio nos dias de hoje não é mais como nos anos 80, ou pelo menos não poderia ser. Isto porque as crianças e adolescentes criados no período pós-moderno possuem características muito distintas dos que viveram no período moderno ${ }^{1}$. As possibilidades de expressão na internet parecem tê-los tornado mais questionadores, curiosos e autônomos, no sentido de saber onde encontrar a informação que lhes interessa/ de que necessitam, na hora que quiserem, graças às novas formas de atuação, às novas redes que surgiram. São, nos termos de Gee (2000, p. 43), "novas pessoas em novos mundos", cujo contato com outras formas de pensar, de produzir e adquirir conhecimento lhes dá a chance

\footnotetext{
${ }^{1}$ Fazemos uma distinção entre os períodos moderno (pré-advento da internet) e pós-moderno (globalização contemporânea, redefinição espaçotemporal), a fim de salientar a necessidade de um repensar sobre a formação de professores de línguas estrangeiras frente às mudanças que essas fases causaram na vida de muitas pessoas.
} 
V. 8 (3)

$300-319$

out-dez

2018

de relativizar o que é local e global através de experiências pessoais, que resultam em uma complexidade de padrões emergentes. As práticas de letramentos digitais, por exemplo, estão vinculadas a um novo ethos que aciona valores e sensibilidades diferentes dos vinculados aos letramentos convencionais (LANKSHEAR; KNOBEL, 2007, 2011). Entendemos que essa condição está diretamente atrelada à fomação de professores, por representar fluxo, produção e geração de conhecimento, responsáveis por novos modelos de desenvolvimento (CASTELLS, 2003) e, desse modo, de interesse dos profissionais que lidam com a relação entre o pensamento e a linguagem.

A partir dessas ponderações, discutimos, neste artigo, a discrepância entre os modelos de ensino de língua tradicionais e as características deste novo século, o descompasso que há entre a teoria e a prática e destacamos a importância das competências linguística e pedagógica para o desempenho do professor de línguas. Baseados em pesquisas na área da linguística aplicada (cf. CONSOLO, 2017; JORDÃO, 2014; GIMENEZ, 2015; MICCOLI, 2013; MONTE MOR, 2015; MOITA LOPES, 2011, 2013; PENNYCOOK, 2017; RAJAGOPALAN, 2013), tratamos de questões de ensino e aprendizado de línguas nesse contexto, no processo de formação de professores no Brasil e propomos uma formação atrelada ao treinamento ${ }^{2}$ do professor de inglês, tendo em vista o desenvolvimento das competências citadas.

Compartilhamos com os autores citados a noção de que sintonizar novas formas de ensinar e aprender com a nova condição de mundo e de sujeitos aprendizes é urgente. Estamos cientes, todavia de que, quando se trata de educação, o sentido do adjetivo 'urgente' venha perdendo o sentido, dentre outros motivos, por não ser uma situação inédita. A história do ensino de línguas no Brasil é tida como um fracasso desde os anos 60 (até 1996), segundo Cox e AssisPeterson (2008), devido, dentre outros fatores, a não obrigatoriedade da língua estrangeira (doravante LE) no ensino básico fundamental, salas numerosas, professores despreparados, etc. A diferença é que, com a abertura da internet, um meio de sociabilidade sem fronteiras característico da atualidade, muitos têm a chance de expandir suas experiências, estar em contato com a heterogeneidade da linguagem de forma significativa e independente da escola. As múltiplas condições

${ }^{2}$ Treinamento, nesse caso, refere-se ao conhecimento de técnicas de ensino, geralmente prescritas por abordagens estruturais, mas de forma consciente, em consonância com um ensino crítico de línguas. 
de expressão e acesso ao conhecimento incentivam a reflexão sobre a diversidade de discursos, a partir do contato com diferentes sistemas de referências, em um ambiente distinto de organização, como é o caso da internet. Como professores de línguas e consumidores da cultura imersa nas novas tecnologias (que molda formas de pensar), temos o desafio de:

assegurar que nossos alunos adquiram a consciência crítica para que compreendam o panorama do letramento contemporâneo e então possam participar ativamente da vida após a escola e no trabalho como cidadãos informados e ativos" (SNYDER, 2009, p. 33).

É também o que advogam as Orientações Curriculares Nacionais para o Ensino Médio (2006) e as pesquisas de linguistas aplicados, voltadas à educação. Dentre os objetivos desse documento, na parte das línguas estrangeiras, estão: "desenvolver a consciência social, criatividade, mente aberta para conhecimentos novos (...)" (MONTE MOR; MENEZES DE SOUZA, 2006, p. 90); ir "além de meramente capacitar o aprendiz a usar uma determinada LE para fins comunicativos." (ibid., p. 92); relacionar o ensino de línguas aos conceitos de cidadania, inclusão/exclusão, etc., utilizando os temas transversais; apresentar a linguagem dentro de contextos linguísticos significativos (BRASIL, 1998; PAIVA, 2009, 2011; MONTE MOR, 2015); trazer para a sala de aula temas que mostrem outras formas de organizar o pensamento, incentivando, assim, a consciência crítica (MONTE MOR; MENEZES DE SOUZA, 2006; PENNYCOOK, 2006), dentre outros.

Para ilustrar nosso ponto de vista, analisamos dois planos de aula de língua inglesa para uma turma de $7^{\circ}$. ano de nível fundamental, confeccionados por dois professores em formação, que cursavam o $7^{\circ}$. semestre do Curso de Letras de uma universidade pública. A escolha de dois entre vários planos de aula produzidos levou em conta características marcantes em relação ao foco restrito na forma (plano 1) e ao foco no uso (plano 2), que denunciam descompassos e avanços nas propostas, tendo em vista o novo cenário que descrevemos neste artigo.

\section{Novo cenário, novas práticas}

As exigências da aplicação das novas tendências para o ensino de línguas na era digital parecem ser mais urgentes do que em outras épocas, quando um novo método de ensino surgia para atender às 
v. 8 (3)

300-319

out-dez

2018

novas necessidades da sociedade. Isto porque a facilidade de acesso à informação global e a outras formas de viver a vida, após a quebra de barreiras geográficas, tornou a criação e o compartilhamento de conteúdo disponíveis para qualquer pessoa com acesso à internet. A negociação de sentidos entre pessoas que falam línguas diferentes, por exemplo, pode ser a base para a participação, o acesso e a criatividade, características que vão ao encontro de uma formação plural. Nesse sentido, Snyder (2009) argumenta que a função da escola na era eletrônica não é somente a de ensinar melhores maneiras de se comunicar, mas a de responder criticamente às situações que emergem nesse novo sistema global. A disciplina de LE pode contribuir para essa formação, porque o conhecimento de outra língua por si só expande horizontes (possibilitando o acesso a outras culturas por meio do conhecimento da língua). O professor de LE pode fazer isso promovendo aulas contextualizadas, com foco nos letramentos e mais no uso do que na forma, de modo a conectar aspectos linguísticos a significados sociais (FAIRCLOUGH, 1992), que mesclam cenários locais e globais, cuja compreensão visa culminar em posturas mais participativas em prol de um bem-estar comum a todos. O professor reflexivo é essencial nessa construção porque a mídia vende a ideia de que o consumo da produção global é benéfico para os que se rendem a ela, afinal, são práticas populares e autorizadas globalmente. O silenciamento da escola sobre questões como essa, ou ainda, o convite do professor de línguas à participação de forma acrítica (destacar os verbos presentes em uma música com conteúdo sexista, por exemplo) perpetuam a formação de sujeitos passivos, registram o descompromisso da escola no que concerne a questões sociais mais amplas, além de insistir no ensino estritamente baseado na estrutura da LE.

Nesse sentido, o desafio de ensinar inglês sob uma perspectiva discursiva (e menos formal) é urgente no contexto onde atuamos, devido à falta de modelos que inspirem futuros professores, afinal estes aprenderam em uma época ${ }^{3}$ em que o ensino era pautado exclusivamente no método tradicional. Apesar das recorrentes e antigas críticas a esse método, o advento tecnológico e as novas necessidades

\footnotetext{
${ }^{3}$ No 'lugar' do qual falamos, há alunos que se formaram há mais de 10 anos e há os que acabaram de sair do ensino médio. A diferença mais marcante entre esses dois períodos refere-se aos recursos e às possibilidades disponíveis mais recentemente, por exemplo, o uso do Datashow, o acesso (do professor) à internet, a possibilidade de programação de aulas híbridas (aplicativo de ensino de línguas e aula presencial) e as raras visitas ao laboratório de informática. A metodologia de ensino e o enfoque na forma continuam dominando as aulas de língua inglesa nas escolas.
} 
das sociedades em seus contextos locais - por exemplo, quando novas formas de expressão começaram a ser parte intrínseca do cotidiano - o uso exclusivo do método tradicional ficou em escancarada evidência. As possibilidades de acesso constante e diário a outras línguas, por meio de vídeo, bate-papo, reportagens, grupos de afinidades, etc. fazem com que o ensino tradicional e descontextualizado da língua inglesa na escola seja compreendido pelos aprendizes como 'chato' e irrelevante. A apropriação, na escola, das oportunidades disponíveis na internet (aplicativos de ensino de línguas, comunicação mediada, blogs, redes sociais, fanfics, etc) representa uma oportunidade riquíssima de contato e aprendizado da língua e trabalho com os multiletramentos, em contextos de interesse do público-alvo. Esta é uma questão urgente e que não pode ficar restrita ao meio acadêmico.

A opção de entrada nas universidades públicas, desde 2009, por meio da nota do ENEM ao invés do exame de vestibular é mais um dos motivos pelos quais o foco no aspecto discursivo da LE é relevante para a formação escolar. Enquanto o vestibular prioriza uma avaliação voltada às estruturas linguística e gramatical (o que vai de encontro aos objetivos propostos pelos documentos oficiais brasileiros que regem a educação), o modelo de avaliação do ENEM objetiva uma compreensão contextualizada do conteúdo, aplicada à experiência do candidato ${ }^{4}$.

Nossa motivação para a escrita deste artigo parte da noção de que a insistência no uso exclusivo do modelo tradicional de ensino5, além de estar atrelada à naturalização deste na cultura escolar, também está relacionada à falta da competência linguística de alguns professores, que, embora pareçam compreeender (na teoria) a importância do ensino contextualizado, interativo e discursivo no ensino de uma língua, na prática denunciam a falta de intimidade que têm com a língua que ensinam. A seguir, discorremos sobre este tema.

\footnotetext{
${ }_{4}^{4}$ Assim como o ENEM sofreu alterações em seu modelo de avaliação desde o ano em que foi implantado, em 1998, (menos decorativo e mais abrangente), o vestibular também tem sofrido alterações quanto aos seus objetivos, indo cada vez mais ao encontro de uma forma menos conteudista e mais global de conhecimento. De qualquer modo, o histórico da exigência do conhecimento estrutural como condição de entrada (no vestibular) para o ensino superior pode ter tido/ser influência na condução da disciplina de LE na escola.

${ }^{5}$ Reconhecemos que o ensino tradicional teve sua importância e funcionou para muitos estudantes durante muitas décadas. Todavia, salientamos que a nova dinâmica sociocultural e econômica provocada pelos movimentos da globalização contemporânea exige um repensar de práticas e metodologias. Nessa perspectiva, o método tradicional pode ser associado a outro modelo, como o funcional, por exemplo, que considera o uso, mas não despreza a gramática.
} 
v. 8 (3) 300-319 out-dez 2018

Um problema marcante no ensino de língua inglesa no Brasil na escola pública é a falta da competência comunicativa da língua por parte de muitos professores (CONSOLO, 2017), o que os impede de se expressarem e de prepararem aulas mais dinâmicas e condizentes com as necessidades dos alunos. O domínio das habilidades e competências não é uma exigência para o ingresso na profissão, conforme detectamos nos documentos que regem as licenciaturas de Letras-português/LE, o que permite que professores não fluentes atuem com insegurança ${ }^{6}$, por não dominarem a língua que ensinam, para programar atividades autênticas, como o uso de áudio ou escrita de uma propaganda, por exemplo.

O descompasso entre o modelo de sala atual da escola (modernidade) e o modelo de aluno ali presente (pós-modernidade) também interfere no aprendizado porque, ainda em muitos contextos, a sala de aula tem uma estrutura analógica, os alunos sentam em fileiras e têm o papel e o lápis como recursos e, às vezes, o livro didático com figuras e artigos que estão longe de sua realidade local. Enquanto isso, a internet incentiva o aprendizado colaborativo, em rede, por meio de escrita, som e imagem, tudo ao mesmo tempo. Nos celulares, computadores e tablets, os alunos têm acesso a uma infinidade de informação e conhecimento. Diante dessa diferença, a sala de aula, sem associação nenhuma ao mundo digital, passa a ser um lugar sem sentido para os aprendizes.

Tendo em vista a formação do professor de línguas estrangeiras, observamos nas aulas de língua materna, no curso de licenciatura no qual atuamos, a ênfase dada à concepção interacional da linguagem e as críticas aos modelos que tratam a língua como expressão do pensamento ou mero instrumento de comunicação. Os professores em formação, então, tendem a compreender as aulas de língua portuguesa como um espaço de interação, onde os gêneros que estão no mundo fora da escola - artes em geral (música, poesia, etc), notícias, seriados de TV, propaganda - são parte essencial do conteúdo. Planejam, a partir daí, projetos de ensino contextualizados, que contemplam multiletramentos, com embasamento teórico denso e uma prática que condiz à proposta desses projetos?

6 Embora conscientemente tentando "desvencilhar-se dos padrões antigos determinados por práticas não contestadas" (CELANI, 2004, p. 39).

7 Ver, por exemplo, a publicação organizada por Rojo (2013). 
O mesmo parece não ocorrer nos estágios de língua inglesa. A concepção dialógica da linguagem é colocada de lado e a LE é tratada como uma língua morta, limitada ao conhecimento lexical e gramatical que às vezes aparecem em algumas músicas de uma outra língua inglesa, uma língua que vive e é dinâmica, mas que é diferente do inglês que se ensina/aprende na escola. Nossa experiência na disciplina de estágio supervisionado de inglês, na observação de aulas nas escolas e no discurso dos professores em formação, indica que a falta de prática na confecção e na escolha de material (autêntico) que possibilite uma discussão em sala mais ampla, voltada a práticas mais proximas de sua realidade (e que fomente uma consciência social) é um empecilho, mas a falta da competência linguística do professor em formação é o maior dos problemas. Além disso, há uma falta de clareza quanto aos objetivos de se aprender a língua inglesa na universidade (para formar professores) e o de se aprender na escola (para formar cidadãos), ou seja, um descompasso entre a teoria e a prática que não tem espaço para discussão durante o período de formação.

Assim, a lacuna entre o novo ethos e os velhos hábitos que permanecem nas práticas escolares é um desafio para o ensinoaprendizagem de línguas estrangeiras, porque o ensino estrutural dessas línguas está naturalizado na educação formal, embora esteja em desajuste gritante com o contexto atual. Sobre a ideologia que nos constituiu ao longo do percurso escolar e de formação profissional, Coracini (2009, p. 157) pondera que:

(...) fomos formados para compreender que a aprendizagem de uma língua se reduz à aquisição, ou melhor, à assimilação de um certo número de formas linguísticas especialmente escolhidas conforme o nível que se encontra o aluno ou aluna, tornando possível a ele ou a ela atingir um patamar cada vez mais sofisticado de comunicação com os nativos.

Nessa perspectiva, o público-alvo, as condições de ensino e as necessidades dos aprendizes não são levados em conta e, em muitos casos, não percebemos essa incoerência quando estamos ensinando ou aprendendo línguas estrangeiras porque a tendência, seja por questões culturais e históricas ou pela própria dinâmica do ensino e aprendizado de línguas ${ }^{8}$, é separar a teoria da prática.

\footnotetext{
${ }^{8}$ Queremos dizer que, para se aprender uma LE, é preciso praticá-la, vê-la em ação em contextos significativos de uso, conhecer sua estrutura para a comunicação e compreensão de seu funcionamento. Assim, acreditamos que é preciso estudar as estruturas, fazer exercícios que não correspondam à concepção dialógica da linguagem,
} 
v. 8 (3)

300-319

out-dez

2018

\section{Integração das competências linguística e pedagógica}

Muito se tem discutido sobre o aprimoramento da formação docente no Brasil (CELANI, 1998; CONSOLO, 2017; BOHN, 2009; GIMENEZ, 2009; 2015; LIBERALI, 2010, etc). Dentre esses estudos, o papel do professor de línguas como um agente reflexivo, comprometido com a justiça social é uma das características essenciais na atualidade. No entanto, para que a formação crítica seja eficaz, o domínio das competências linguística e pedagógica é essencial para a compreensão das mensagens do texto, da sua construção em termos linguísticos e também dos modos de abordagem do texto, tendo em vista a faixa etária dos aprendizes, seu conhecimento de mundo, da LE e das conexões que são capazes de fazer com o contexto onde vivem. Dessa forma, várias frentes são necessárias para uma formação completa, que, todavia, são constantemente inviabilizadas nas universidades brasileiras, principalmente pela falta de uma política que incentive o aprendizado de LE (GIMENEZ, 2009). Isso se reflete de variadas formas que vão desde o oferecimento de carga horária escassa para as disciplinas específicas relacionadas a metodologias, práticas e didática no ensino de LE nos cursos de dupla licenciatura, até a falta de infra-estrutura para a utilização de laboratórios e de internet e produção de material.

Em tais disciplinas, há de se focar, por exemplo, na competência linguística de um professor (além do ensino da língua), atrelada a propósitos comunicativos específicos para a atuação em sala de aula (que pode ser diferente da necessidade para a atuação em outros contextos), principalmente quanto à oralidade, visando à qualidade do ensino (CONSOLO, 2004). Orientações e práticas nesse sentido constribuiriam sobremaneira na construção da identidade desse professor e no estabelecimento de seus objetivos profissionais. No que se refere à proficiência do professor, Scaramucci (2000, p. 14) sugere que "em vez de proficiência única, absoluta, monolítica, baseada naquela do falante ideal, teríamos várias, dependendo da situação do uso da língua", ou seja, para o professor de línguas, uma proficiência que permita a abordagem do material na LE e que tenha condições de discuti-lo para além da superfície. A noção de proficiência, nesse sentido, é importante

corrigi-los, refazê-los, às vezes, de modo sistemático, com o foco na forma. O que defendemos neste trabalho é que o cerne do aprendizado não pode ser a memorização de conteúdo gramatical, a língua como estrutura ou código. Esses devem agir como coadjuvantes na preparação para o uso da linguagem de forma interacional, na produção e compreensão de sentidos. 
para que o professor tenha condições de se situar no universo do ensino de LE (o quanto eu sei e o quanto eu preciso saber). Schmitz (2009) salienta que o papel das universidades é preparar os alunos, ou seja, os futuros professores de línguas, nas quatro habilidades. Destacamos que essa preparação exige não somente o ensino baseado na prática (o foco no uso), mas também no como ensiná-la, procedimento que tem certa conexão com o foco na forma.

Quanto à competência pedagógica, o domínio da metalinguagem reflete o nível de profundidade da relação do professor com a LE, na abordagem de conteúdos e habilidades, permitindo-lhe identificar situações de sala de aula e traçar direcionamentos com base científica. Em consonância com sua experiência no processo de ensino e aprendizagem (sem base teórica), a competência pedagógica legitima o conhecimento prático (pós-formação) que perpassa sua atuação profissional por meio de sua bagagem teórica. Miccoli (2013) refere-se a uma visão bem informada "às habilidades que professores devem desenvolver para defenderem suas escolhas de ensino" ( $p$. 14). Uma linguagem ou um conhecimento específicos para atuação pedagógica podem abrir possibilidades para que o professor elabore o seu planejamento e atue na sala de aula, aliando fatores conceituais (visão de linguagem, relações entre língua materna e LE, concepção de erro, adequação de metodologias, ensino de gramática, etc) à sua experiência como aprendiz na escola regular, na universidade e na sua atuação profissional. Zeichner e Liston (1996) ponderam que a reflexão acontece quando os professores começam a questionar as suas práticas. A competência pedagógica pode oferecer subsídios para um questionamento que parta de experiências prévias, reconhecidas cientificamente.

Argumentamos que a falta dessas duas competências ou de uma delas provoca efeitos em outras dimensões do ensino de LE. A falta de criticidade, por exemplo, na escolha do conteúdo (puramente estrutural ou envolto por ideologias dominantes) é uma questão que exige a prática reflexiva tanto no período de formação do professor, quanto na atuação em sala de aula. Por ser um tema recorrente na formação, inferimos que o ensino voltado exclusivamente à estrutura (centrada na explicação do livro didático e que não abre para a experiência do aluno) parece assegurar ao professor o domínio da aula, uma vez que ele não possui a competência linguística que o permite trilhar um caminho sujeito a imprevistos. Já na escolha de temas para a sala de aula, observarmos 
v. 8 (3)

300-319

out-dez

2018

uma tendência que (ainda) supervaloriza o 'outro' estrangeiro em detrimento do local, por exemplo, músicas norte-americanas, marcas de roupas, monumentos internacionais, assim como mostrou a pesquisa de Moita Lopes, realizada há mais de 20 anos, em 1996, na obra 'Oficina de linguística aplicada: a natureza social e educacional dos processos de ensino e aprendizagem de línguas'. Ademais, a apresentação de temas seguros, que não condizem com questões atuais, tais como o conceito de família nuclear e o silenciamento sobre outras configurações de família, é recorrente nas salas de aula pesquisadas. Nesses casos, identificamos muitos professores desatentos a questões de discurso e poder, ou seja, a ausência de um foco político no ensino de línguas, de uma visão ética atenta a questões de desigualdade e opressão que, segundo Pennycook (1999), integram o perfil exigido do professor deste século. Há ainda o apagamento de reações negativas de aprendizes em relação à língua inglesa, além da propagação (velada ou não) da desvalorização da cultura local. Pennycook (1998) discute a suposta neutralidade da língua inglesa na condição de base para a comunicação global e critica os professores de línguas que se pautam no ensino meramente funcional da língua, apontando essa abordagem como perpetuadora da manutenção das desigualdades. Sugerimos que atitudes como essa podem se agravar com a ausência das competências apresentadas neste artigo, pois denunciam a falta de entrosamento do professor com o seu objeto de trabalho.

Menezes de Souza (2002) assevera que, na sala de aula tradicional, conteúdo e metodologia são vistos como fixos e estáveis. Esse autor faz alusão à visão saussuriana da linguagem para expor situações da sala de aula tradicional. Para a sala de aula compreendida como um fenômeno social e ideologicamente constituído, sugere uma reflexão sobre a visão bakhtiniana da linguagem, vista como "uma arena de conflitos de vozes e valores mutáveis concorrentes (...) que permite a negociação em sala de aula" (p. 23-24). Argumentamos que essa negociação, no entanto, só é possível se o professor estiver seguro quanto ao seu papel nessa arena, papel atrelado às competências desejáveis para um professor de LE.

A fim de ilustrar essa discussão, a seguir apresentamos dois planos de aula elaborados por professores em formação, para aplicação no $7^{\circ}$. ano do ensino fundamental de uma escola pública. 


\section{Teoria e prática: construção de interação na sala de aula de língua inglesa}

Os dois modelos de planos de aula apresentados a seguir têm características distintas: um é descontextualizado, construído com base no modelo tradicional de ensino e o outro é contextualizado, de cunho mais interacionista (LEFFA, 2016; MONTE MOR e MENEZES DE SOUZA, 2006; PAIVA, 2011; SILVA; PARREIRAS, FERNANDES, 2015). Os professores em formação tiveram como base teórica os PCN (BRASIL, 1998), as OCEM-LE (BRASIL, 2006), artigos sobre letramentos e as metodologias de ensino de línguas estrangeiras e as novas tendências deste ensino. Foram dadas as mesmas instruções: elaborar um plano contextualizado de $1 \mathrm{~h} / \mathrm{a}$, com base nas discussões em sala de aula. Como ponto de referência, os planos deveriam incluir um verbo modal como ponto gramatical. Trata-se, a seguir, do primeiro rascunho do processo de confecção. O participante 1 apresentou o plano de aula 1, transcrito a seguir.

Plano de aula 1

Objetivos geral: apresentar o uso dos modal verbs;

Objetivos específicos: identificar o conhecimento prévio dos alunos; praticar exercícios do conteúdo gramatical - Modal verbs May e Might;

Procedimentos metodológicos:

$1^{\mathbf{0}}$ momento: apresentação e chamada.

$\mathbf{2}^{\mathbf{0}}$ momento: perguntar para os alunos se eles já estudaram os Modal Verbs para identificar o conhecimento prévio; explicar sucintamente o conceito do conteúdo através de exemplos e transcrições básicas escritas na lousa.

$3^{\mathbf{0}}$ momento: Ouvir a música It might be you (Stephen Bishop) para trabalhar os Modals. Eles ouvirão a música uma vez e, em seguida, entregarei a mesma digitalizada para ouvirem e circularem os Modal Verbs. Para finalizar, realizaremos a correção e cantaremos juntos.

Alguns exemplos de ideias que os modal verbs podem expressar: May I use your umbrela? (permissão) - (Posso usar seu guardachuva?)

It might rain this afternoon. (possibilidade) - (Poderia chover esta tarde.) 
v. 8 (3)

300-319

out-dez

2018

O plano 1 não menciona e não inclui uma contextualização para o ensino do ponto gramatical 'verbos modais'. A forma é privilegiada em detrimento do uso, uma vez que o professor iniciaria perguntando se os alunos já teriam estudado os verbos modais ao invés de apresentar um exemplo e incentivar/checar a compreensão. Ainda no segundo momento, não foi planejada uma ação a partir da resposta 'sim' ou 'não' para a pergunta 'vocês já estudaram os modal verbs?', ou seja, o plano não prevê uma negociação do aluno com o conteúdo proposto. O fato de a música ter sido incluída no $3^{\circ}$. momento não significa que o contexto seria usado porque a função dos alunos seria a de meramente circular os modais may e might, sem se ater ao sentido ou ao que os precedem ou sucedem. Ou seja, o foco no uso não seria explorado, tampouco os saberes contextuais, assim como apontam outros estudos com enfoque na gramática da $\mathrm{LI}^{9}$. A música pareceu ser só um pretexto para que a aula ficasse mais interessante para os alunos, sem a preocupação de aproximar-se de questões, tais como os objetivos da aula, o conteúdo ideológico da música, etc. A não ser pela gramática, os dois exemplos dados no final do plano vêm desconexos de qualquer atividade às quais os alunos poderiam fazer uma associação. Esses exemplos também apontam para o planejamento mecânico da atividade anterior (circular os 'modal verbs' na música). Do contrário, a identificação dos modais na canção poderia ser a base para o trabalho com ambos: a compreensão da gramática e dos aspectos discursivos do material escolhido. Do ponto de vista das competências linguística e pedagógica, a descrição, no segundo momento do plano, "explicar sucintamente o conceito do conteúdo através de exemplos e transcrições básicas escritas na lousa" sugere que a brevidade da explicação será pautada no que o material didático indicar, já que os exemplos que os alunos poderiam trazer, não são previstos no plano. Entendemos que esses exigiriam a atuação das competências do professor. Do mesmo modo, a menção às transcrições 'básicas', no plano, denotam uma falta de familiaridade com a línguaalvo, uma vez que inferimos que o exemplo "may I use your umbrella?" pode ser considerado mais descontextualizado e complexo do que, por exemplo, "you may close your notebooks now". A competência pedagógica não foi identificada nesse plano.

A seguir, apresentamos o plano de aula 2.

9 Sobre o ensino de gramática, ver por exemplo, Pontara e Cristovão (2017) e Lopes e Silva (2018). 
Plano de Aula 2

Objetivos geral: apresentar os verbos modais de modo contextualizado;

Objetivos específicos: praticar o verbo modal should e seus principais usos; produzir sentenças usando o verbo modal should, a partir de um tema proposto; praticar o listening através da música. Procedimentos metodológicos:

$\mathbf{1}^{\mathbf{0}}$ momento: Apresentar o verbo modal should. Para que os alunos compreendam e possam desenvolver suas estratégias e competências, apresentaremos o comercial televisivo "Teste drive Claro" (https:// www.youtube.com/watch?v=6qStZE7pwb8) com cenas ilustradas pela música "should I stay or should I go" ao fundo. O vídeo apresenta várias situações de escolha e dúvida (pular na piscina ou não, cortar o cabelo ou não, etc), indicando ações a serem tomadas. Should é um verbo modal que indica dúvida e conselho. Após o vídeo, levantaremos uma discussão sobre o tema, tentando construir um significado acerca de decisões: "vocês têm dificuldade para decidir algo?"; "são muito indecisos?"; como podemos identificar a dúvida na pergunta should I stay or should I go?; "o que você acha que o garoto 1 deveria fazer? (He should jump); "e o 2 "?

$2^{\mathbf{0}}$ momento: Praticar o should: os alunos deverão construir um quadro com conselhos do que fazer e não fazer na sala de aula (you should/ you shouldn't). Essas sentenças serão fixadas no mural da escola, visando a conscientização sobre comportamento na escola, na visão dos alunos.

$3^{\mathbf{0}}$ momento: Correção na lousa.

$4^{0}$ momento: Reproduzir a música should I stay or should I go?. Os alunos deverão preencher as lacunas que estão faltando, compreender o tema central da canção e cantar no final, após a correção.

Diferentemente do plano 1, o contexto e o foco no uso fazem parte dos objetivos da aula de verbos modais, para apresentação do 'should'. Essa tem início com a apresentação de um vídeo com situações (foco no uso) de pessoas indecisas na tomada de decisões. A aula inclui discussão para certificação do sucesso ou fracasso da apresentação e de perguntas que incluem o aluno, ou seja, sua interação com o conteúdo apresentado é levada em consideração. O quadro com conselhos também privilegia a participação do aluno na construção de um saber contextualizado, um saber significativo para o contexto dos alunos. 
v. 8 (3)

300-319

out-dez

2018

Apesar de não especificar como será feita a compreensão do tema da música, o plano sinaliza a atenção para esse momento da aula e não somente para o 'cantar por cantar'. Outro ponto a ser destacado é que as lacunas a serem preenchidas (no $4^{\circ}$. momento) não são apresentadas no plano. Todavia, consideramos esse fato esperado na orientação do refazimento de planos de aula que frequentemente trazem resquícios dos modelos de aprendizagem naturalizados. Quanto aos objetivos gerais, esses não foram totalmente contemplados porque somente 1 modal foi apresentado. Entretanto, entendemos que esse ato não prejudicou o desenvolvimento do que foi apresentado na aula. Seria preciso observar se, na avaliação, o conhecimento de outros verbos modais foi exigido.

No geral, o plano 2 sinaliza a preocupação com a compreensão dos objetivos do plano (pelo menos o modal 'should'), dentro de um contexto que leva em conta a participação do aluno e não somente o item gramatical apresentado. Identificamos a competência linguística na proposição do verbo modal 'should', pois entendemos que a professora estagiária escolheu apresentar o que ela domina, o que tem segurança para ensinar. Essa segurança está materizalizada nos tipos de atividades que propõe (conteúdo autêntico e construção de sentenças). Visualizamos a competência pedagógica na proposição do vídeo em associação com o conteúdo que pretende ensinar - o material escolhido está em consonância com os significados do verbo modal 'should', o que sugere a familiaridade da aluna com o tema.

Ao todo, sete planos foram confeccionados após as orientações e discussões teóricas nas aulas de estágio. Escolhemos os dois planos apresentados nessa seção devido aos objetivos muito distintos que propõem para o mesmo conteúdo e ainda para mostrar como o processo de absorção das novas teorias não acontece de uma hora para outra para todos. Mesmo com o acesso às mesmas teorias sobre as novas tendências para o ensino de línguas, os procedimentos propostos pelo professor estagiário 1 foram pautados nas normas do ensino de gramática descontextualizada, com foco na forma, ou seja, mais presos ao modelo de ensino ao qual foi submetido. Além disso, o plano denuncia uma possível falta das competências discutidas neste artigo.

Dos sete planos confeccionados por essa turma, quatro pautaramse, de forma geral, mais na forma e três, mais no uso. Constatamos, por meio da aplicação de amostras de testes internacionais, que os três menos atrelados à forma foram confeccionados por professores em formação com nível de competência linguística superior aos dos outros professores. Assim, 
embora um estudo mais aprofundado seja necessário para investigar a relação entre as competências e o enfoque dado à forma/ ao uso, neste trabalho especificamente, sugerimos que a falta de domínio da língua parece ser um fator determinante para o planejamento de exemplos e atividades que não privilegiam a interação, pois, além de influenciar o modo como o professor se relaciona com a língua na preparação das aulas (antes), expõe (durante a aula) sua deficiência em relação à LE. Esse é um risco que, naturalmente, ninguém quer correr, principalmente os recém-formados que ainda não têm sua identidade de professor solidamente construída.

A discussão coletiva dos planos, durante a disciplina e o acompanhamento das miniaulas pela professora responsável epelos colegas de sala, foram positivamente avaliados e mostraram-se importantes no refazimento e no repensar dos objetivos, metas e ações dos planos 1 (e demais planos) e para os ajustes no plano 2 apresentados neste trabalho. Foi possível perceber a reorganização e redirecionamento dos momentos da aula, a partir da observação dos trabalhos e relatos dos colegas.

\section{Considerações finais}

Tendo como parâmetros a conjuntura atual dos Cursos de Letras no Brasil, propomos que o aprendizado e a prática da língua inglesa de professores em formação, dentro e fora da universidade, são primordiais, pois o domínio da língua é um dos pontos que poderá garantir um aspecto ausente nas aulas que observamos: a segurança do professor de línguas para ensinar o que precisa ensinar. A universidade, por sua vez, deve garantir e promover a prática associada à teoria desde o início da graduação, pois muitos professores em formação pisam em uma sala de aula na escola regular (principalmente de LE) somente no penúltimo semestre do Curso, conforme tem mostrado nossa experiência na disciplina de estágio de inglês. A esse respeito, ações como as promovidas pelo PIBID ${ }^{10}$ e a garantia de um Centro de Ensino de Línguas Estrangeiras nas universidades, específico para os futuros professores de línguas, são iniciativas que, de forma periférica, vão ao encontro do respeito aos diferentes tempos e formas de aprender, já que garantem espaços de prática, reflexão e aprendizado durante todo o percurso da formação do professor.

\footnotetext{
${ }^{10}$ Programa Institucional de Bolsas de Iniciação à Docência (PIBID). Como coordenadora de um projeto do PIBID, podemos dizer que os bolsistas que participam desse programa adquirem um know-how, no que se refere à relação teoria e prática, ideal para o contexto em que vão atuar.
} 
v. 8 (3)

$300-319$

out-dez

2018

Por sua vez, pensando nos professores em atuação, é desejável que escolas e secretarias de educação promovam práticas de ensino nos horários destinados a reuniões de planejamento/projeto (teoria), com a proposição de minicursos e oficinas mais específicos de cada disciplina.

Paralelamente a essa ação, uma alternativa para o domínio da língua inglesa desejável para o professor de línguas seria a oferta, pelo governo, de condições para o estágio desses professores em países onde se fala a língua que vão ensinar. Embora o domínio da língua-alvo não seja necessariamente uma condição para um ensino de qualidade, tal domínio é um requisito fundamental para o professor, além de experiências culturais em contextos de uso dessa língua.

Quanto às limitações deste estudo, observamos que o tempo para o amadurecimento das competências linguística e pedagógica e para o refazimento dos planos durante o processo de estágio não acompanhou o tempo destinado à disciplina. Modelos tradicionais de ensino persistiram, apesar de o enfoque da disciplina ter sido voltado para as novas práticas de ensino e aprendizagem na contemporaneidade (LEFFA, 2016; LOPES e SILVA, 2018; PAIVA, 2011; MOITA LOPES, 2013).

Finalmente, acreditamos que seja dever de todos pensar na formação para a educação e para o contexto social em conjunto com o aprendizado da língua: esse é o desafio que o professor de línguas/ (todos) tem/(têm) pela frente. Também não podemos deixar de registrar que os resultados de pequenas ações na disciplina de estágio, no PIBID e no trabalho em parceria com as escolas estaduais apontam que a abertura de espaços para reflexão em programas de formação (na graduação e formação continuada) de professores tem provocado mudanças positivas na prática pedagógica do professor.

\section{Referências}

BOHN, H. O método "soberano" para o ensino e aprendizagem da língua inglesa. In: Ensino e aprendizagem de língua inglesa: conversa com especialistas. São Paulo: Parábola, 2009. p 169-178.

BRASIL. Ministério da Educação. Secretaria de Educação Básica. Orientações curriculares para o ensino médio. Linguagens códigos e suas tecnologias: conhecimento de línguas estrangeiras. Brasília, DF: 2006. Disponível em http://portal.mec.gov/seb/arquivos/pdf/book_volume_01 internet. pdf acesso em 27 de agosto de 2016.

BRASIL. Ministério da Educação. Secretaria de Educação Básica. Parâmetros curriculares nacionais: terceiro e quarto ciclos do nível fundamental: línguas estrangeiras. Brasília, DF: 1998. Disponível em http://portal.mec.gov.br/ seb/arquivos/pdf/pcn estrangeira.pdf. acesso em 27 de agosto de 2016. 
CASTELLS, M. A galáxia da Internet: reflexões sobre a internet, os negócios e a sociedade. Tradução Maria Luiza X. de A. Borges. Rio de Janeiro: Zahar, 2003.

CELANI, M.A.A. Transdisciplinaridade na linguística aplicada no Brasil. In: SIGNORINI, I.; CAVALCANTI, M. C. (Orgs.). Linguística aplicada e transdisciplinaridade: questões e perspectivas. Campinas: Mercado de Letras, 1998. p. 129-142.

CELANI, M.A.A. Culturas de aprendizagem: risco, certeza e educação. In: MAGALHÃES, M.C.C. (Org.) A formação do professor como um profissional crítico: linguagem e reflexão. Campinas: Mercado das Letras, 2004. p. 37-56.

CONSOLO, D.A. A construção de um instrumento de avaliação da proficiência oral do professor de língua estrangeira. Trabalhos em Linguística Aplicada, v. 43, n. 2, p. 265-286, 2004.

CONSOLO, D.A. Assessing EFL teachers' oral proficiency: on the development of teacher education programmes and testing policies in Brazil. Campinas: Pontes, 2017. p. 59-71.

CORACINI, M.J. Língua materna-estrangeira: entre saber e conhecer. In: CORACINI, M.J. (Org.). A celebração do outro: arquivo, memória e identidade. Línguas materna e estrangeira) plurilinguismo e tradução. Campinas: Mercado das Letras, 2009. p. 149-162.

COX, M. I. P.; ASSIS-PETERSON, A. A. O drama do ensino de inglês no Brasil. In: ASSIS-PETERSON, A. A. (Org.). Línguas estrangeiras: para além do método. São Carlos: Pedro \& João Ed./Cuiabá: EdUFMT, 2008. p. 97-113.

FAIRCLOUGH, N. Discourse and social change. London: Logman, 1992.

GEE, J. P. New people in new worlds: networks, the capitalism and schools. In: COPE, B.; KALANTZIS, M. (Eds.). Multiliteracies: literacy learning and the design of social futures. New York: Routledge, 2000. p. 43-68.

GIMENEZ, T. Ensinar a aprender ou ensinar o que aprendeu? In: Ensino e aprendizagem de língua inglesa: conversa com especialistas. São Paulo: Parábola. 2009, p. 107-112.

GIMENEZ, T. Renomeando o inglês e formando professores de uma língua global. Estudos linguísticos e literários, v. 52, p. 73-93, 2015. Disponível em https://portalseer.ufba.br/index.php/estudos/article/view/15464/10611. Acesso em 20 de jan. 2018.

JORDÃO, C.M. ILA, ILF, ILE, ILG: quem dá conta? Revista Brasileira de Linguística Aplicada. Belo Horizonte, v. 14, p. 13-40, 2014.

LANKSHEAR C; KNOBEL, M. Sampling "the New" in New Literacies. In: KNOBEL, M.; LANKSHEAR, C. A new literacies sampler. New York: Peter Lang, 2007. p. 01-24.

LANKSHEAR C; KNOBEL, M. Literacies: social, cultural and historical perspectives. New York: Peter Lang, 2011. 
v. 8 (3)

$300-319$

out-dez

2018

LEFFA, V. Redes sociais: ensinando línguas como antigamente. In: ARAÚJO, J.C.; LEFFA, V. (Orgs.). Redes sociais e ensino de línguas: o que temos que aprender? São Paulo: Parábola, 2016. p. 137-153.

LIBERALI, F.C. Formação de professores de línguas: rumos para uma sociedade crítica e sustentável. In: GIMENEZ, T.; MONTEIRO, M.C.G. (Orgs.). Formação de professores de línguas na América Latina e transformação social. Campinas: Pontes, 2010. p. 71-91.

LOPES, M.F.V.; SILVA, C.M.M.B. Atividades de gramática no livro didático de língua estrangeira. Polifonia, v. 25, n. 37.2. 2018. Disponível em http:/periodicoscientificos.ufmt.br/ojs/index.php/polifonia/article/ view/6085/pdf Acesso em 19 de out.

MENEZES DE SOUZA, L.M.T. O conflito de vozes na sala de aula. In: CORACINI, M.J. (Org.). o jogo discursivo na sala de aula: língua materna e língua estrangeira. Campinas: Pontes, 2002. p. 21-26.

MICCOLI, L. Aproximando teoria e prática para professores de línguas estrangeiras. Belo Horizonte: Fino Traço, 2013.

MOITA LOPES, L.P. da. A função da aprendizagem de línguas estrangeiras na escola pública. In:

Oficina de linguística aplicada: a natureza social e educacional dos $\overline{\text { processos }}$ de ensino e aprendizagem de línguas. Campinas: Mercado das Letras, 1996. p. 127-136.

MOITA LOPES, L.P. da. Por uma linguística aplicada INdisciplinar. 3a. ed. São Paulo: Parábola, 2011.

MOITA LOPES, L.P. da. Introdução. Fotografias de linguística aplicada brasleira na modernindade recente: contextos escolares. In: Linguística aplicada na modernidade recente: festschriff para Antonieta Celani. São Paulo: Parábola, 2013. p. 15-37.

MONTE, MOR; MENEZES DE SOUZA, L.M.T. Conhecimentos de Línguas estrangeiras. In: BRASIL. MEC. SEB. Orientações curriculares para o ensino médio. Linguagens códigos e suas tecnologias. Brasília, DF, 2006. p. 87124. Disponível em http://portal.mec.gov/seb/arquivos/pdf/book volume_01_internet.pdf acesso em 27 de agosto de 2017.

MONTE MOR. Crítica e letramentos críticos: reflexões preliminares. In: ROCHA, C.H.; MACIEL, R.F. (Orgs.). Língua estrangeira e formação cidadã: por entre discursos e práticas. Campinas: Pontes, 2015. p. 31-50.

PAIVA, V.L.M.O. O ensino de língua estrangeira e a questão da autonomia. In: LIMA, D.C. (Org.). Ensino e aprendizagem de língua inglesa: conversa com especialistas. São Paulo: Parábola, 2009, p. 31-38.

PAIVA, V.L.M.O. Ilusão, aquisição ou participação. In: LIMA, D.C. (Org.). Inglês em escolas públicas não funciona: uma questão, múltiplos olhares. São Paulo: Parábola, 2011. p. 33-46.

PENNYCOOK, A. English and the discourse of colonialism. Londres: Routledge, 1998.

PENNYCOOK, A. Introduction: critical approaches to TESOL. TESOL Quarterly, V. 33, no. 3, p. 329-348, 1999. 
PENNYCOOK, A. Linguística aplicada transgressiva. In: MOITA LOPES, L.P. (Org.). Por uma linguística aplicada Indisciplinar. São Paulo: Párábola, 2006. p. 67-84.

PENNYCOOK, A. The cultural politics of English as an international language. 3rd. ed. New York: Routledge, 2017.

PONTARA, C.L.; V.L.L. CRISTOVÃO. Gramática/análise linguística no ensino de inglês (língua estrangeira) por meio de sequência didática: uma análise parcial. Revista D.E.L.T.A., 33.3, p. 873-909, 2017.

RAJAGOPALAN, K. Política de ensino de línguas no Brasil: história e reflexões prospectivas. In: MOITA LOPES, L.P. Linguística aplicada na modernidade recente: festschriff para Antonieta Celani. São Paulo: Parábola, 2013. p. 143161.

ROJO, R.H.R. (Org.) Escol@ conectada: Os multiletramentos e as TICs. 1. ed. São Paulo, SP: Parábola Editorial, 2013.

SCARAMUCCI, M. Proficiência em LE: Considerações terminológicas e conceituais. Trabalhos em Linguística Aplicada, v. 36, p. 11-22, 2000.

SCHMITZ, J. Ensino/aprendizagem das quatro habilidades linguísticas na escola pública: uma meta alcançável? In: LIMA, D.C. (Org.) Ensino e aprendizagem de língua inglesa: conversa com especialistas. São Paulo: Parábola. 2009, p. 13-20.

SILVA, R.C.; PARREIRAS, V.A.; FERNANDES, G.G.M. Avaliação e escolha de livros didáticos de inglês a partir do PNLD: uma proposta para guiar a análise. Linguagem \& Ensino, Pelotas, v.18, n.2, p. 355-377, jul./dez. 2015.

SNYDER, I. Ame-o ou deixe-os: navegando no panorama de letramentos em tempos digitais. In: Araújo, J.C.; DIEB, M. (Orgs.). Letramentos na Web: gêneros, interação e ensino. Foraleza: edições UFC, 2009. p. 23-46.

ZEICHNER, K. M.; LISTON, D. P. Reflective teaching: An introduction. Mahwah, NJ: Erlbaum, 1996. 